\title{
Antiarrhythmic Effect of a New Class 1 Antiarrhythmic Drug, Nicainoprol, on Canine Ventricular Arrhythmias
}

\author{
Keitaro HASHIMOTO, Kentaro AKIYAMA and Harumi MITSUHASHI \\ Department of Pharmacology, Yamanashi Medical College. \\ Tamaho-cho, Yamanashi 409-38, Japan
}

Accepted October 26, 1988

\begin{abstract}
Using two-stage coronary ligation-, digitalis- and adrenaline-induced canine ventricular arrhythmias, antiarrhythmic effects of nicainoprol were examined in dogs, and the minimum effective plasma concentration for each arrhythmia model was determined. Nicainoprol suppressed the arrhythmias, and the minimum effective plasma concentrations for arrhythmias induced by $48 \mathrm{hr}$ coronary ligation. digitalis and adrenaline were $8.9 \mu \mathrm{g} / \mathrm{ml}$ (by $5 \mathrm{mg} / \mathrm{kg}$, i.v.). $3.0 \mu \mathrm{g} / \mathrm{ml}$ (by $3 \mathrm{mg} / \mathrm{kg}$, i.v.) and $2.7 \mu \mathrm{g} / \mathrm{ml}$ (by $3 \mathrm{mg} / \mathrm{kg}$, i.v.), respectively. The concentration for coronary ligation arrhythmia was higher than those for the digitalis and adrenaline arrhythmias. This pharmacological profile is similar to those of aprindine and propafenone. Nicainoprol induced some central nervous system effect including vomiting in conscious coronary ligated dogs. Though intravenous nicainoprol $(5 \mathrm{mg} / \mathrm{kg}$ ) was not effective on $24 \mathrm{hr}$ coronary ligation arrhythmia, an oral dose of 30 to $40 \mathrm{mg} / \mathrm{kg}$ was effective. These results indicate that it may become a clinically useful antiarrhythmic drug.
\end{abstract}

Nicainoprol, 8 - (3 - isopropylamino - 2 - hydroxy-propoxy) - 1 - nicotinoyl-1,2,3,4 - tetrahydroquinoline, is a new synthetic class 1 antiarrhythmic agent, and it was reported to have a shortening effect on the action potential duration of canine Purkinje fiber, but a lengthening effect on that of canine ventricular muscle (1), with slight beta blocking activity (2). Preliminary reports showed that it is effective in animal and clinical arrhythmias $(2,3)$.

We have been reporting effects of various antiarrhythmic drugs using canine ventricular arrhythmia models (4-6) and classified antiarrhythmic drugs based on their pharmacological effectiveness (7). Using the same experimental methods, the present experiment was designed to examine antiarrhythmic effects of the class 1 drug nicainoprol qualitatively and quantitatively in comparison with other antiarrhythmic drugs.

\section{Materials and Methods}

Production of two-stage coronary ligationinduced arrhythmia: Fourteen beagle dogs, weighing $7-9 \mathrm{~kg}$, were anesthetized initially with thiopental sodium. As reported earlier (4), the chest was opened and a two-stage coronary ligation was performed under halothane anesthesia after intubation under intravenous thiopental sodium, $30 \mathrm{mg} / \mathrm{kg}$. Bipolar atrial electrodes were sutured on the left atrial appendage, and polyethylene cannulae were inserted into the left jugular vein and into the left internal carotid artery for injection of drugs and withdrawal of blood samples and for blood pressure recording. respectively.

Experiments were done without anesthesia at 24 and $48 \mathrm{hr}$ after coronary ligation. The lead II ECG, atrial electrogram from the left atrial appendage, and the blood pressure were recorded continuously using telemetry systems (Nihon Kohden and Nishimu Electronics Industries). Intravenous nicainoprol, 5 $\mathrm{mg} / \mathrm{kg}$. was injected through a venous cannula over a period of 3 to $5 \mathrm{sec}$. Rapid bolus injection was used to apply the two compartment model for analysis of the plasma concentration time curves. Venous samples were drawn from the cannula $5 \mathrm{~min}$ before and at $1,3,5,10,15,30$ and $60 \mathrm{~min}$ after injec- 
tion of nicainoprol. For oral administration studies, $30-40 \mathrm{mg} / \mathrm{kg}$ nicainoprol in a gelatin capsule was administered to 6 dogs $24 \mathrm{hr}$ after coronary ligation. Venous samples were drawn up to $24 \mathrm{hr}$ after coronary ligation.

Production of digitalis-induced arrhythmia: Six mongrel dogs of either sex, weighing $8-15 \mathrm{~kg}$, were anesthetized with $30 \mathrm{mg} /$ $\mathrm{kg}$ of pentobarbital sodium. A supplemental dose of $10 \mathrm{mg} / \mathrm{kg}$ was sometimes required. As reported earlier (5), $40 \mu \mathrm{g} / \mathrm{kg}$ ouabain was injected intravenously and then followed by an additional $10 \mu \mathrm{g} / \mathrm{kg}$ every $20 \mathrm{~min}$ until stable ventricular arrhythmia was produced. Nicainoprol, $3 \mathrm{mg} / \mathrm{kg}$, was injected intravenously through a cannula in the femoral vein over a period of 3 to $5 \mathrm{sec}$.

The lead II ECG, atrial electrogram from catheter tip electrodes inserted from the right external jugular vein into the right atrium, and the blood pressure were continuously recorded through a catheter in the right femoral artery. Venous blood samples were drawn from the jugular vein $5 \mathrm{~min}$ before and at $1,3,5,10,15,30$ and $60 \mathrm{~min}$ after nicainoprol injection.

Production of adrenaline-induced arrhythmia: Seven mongrel dogs of either sex. weighing $7-15 \mathrm{~kg}$, were anesthetized initially with thiopental sodium. As reported earlier (6), after intubation. 1.0\%, halothane vaporized with $100 \%$ oxygen was administered with a volume-limited ventilator. Adrenaline was infused through the left femoral vein at a rate of $2.5 \mu \mathrm{g} / \mathrm{kg} / \mathrm{min}$. If multifocal ventricular tachycardia was not induced, a higher infusion rate was employed. At $3 \mathrm{~min}$ after the start of adrenaline infusion, up to 3 $\mathrm{mg} / \mathrm{kg}$ nicainoprol was injected into the right femoral vein over a period of 3 to $5 \mathrm{sec}$.

The lead II ECG, atria! electrogram from the catheter tip electrodes in the right atrium and blood pressure were continuously recorded. Venous samples were drawn from the jugular vein $1 \mathrm{~min}$ before and at 1, 3, 5, 10 and 15 min after injection.

Plasma nicainoprol assay: A sensitive and specific determination of nicainoprol in plasma was performed using the high performance liquid chromatographic method (8). at the Nippon Roussel K.K., Tokyo, Japan.

Determination of the minimum effective plasma concentration: The severity of arrhythmia was expressed by the arrhythmic ratio: number of ventricular ectopic beats divided by the total heart rate. Ventricular beats were judged by the different shape of the ventricular complex from the normal QRS complex. For the arrhythmias used, the arrhythmic ratios before drug injection were almost 1 , and there were no spontaneous improvements in these ratios. If the arrhythmic ratio after drug administration was decreased significantly from the 0 time value $(P<0.05)$, the drug was judged as having an antiarrhythmic effect. For statistical analysis, Student's $t$-test for paired data were used to evaluate the difference as compared to the 0 time values. As reported earlier (4-7), the minimum effective plasma concentration of nicainoprol was determined as follows: The last minute of statistically significant decrease $(P<0.05)$ in the arrhythmic ratio compared with that at 0 time was determined. Then the corresponding plasma concentration was calculated from the experimentally derived plasma concentration-time equations, and this was regarded as the minimum effective plasma concentration.

\section{Results}

Effects of nicainoprol on two-stage coronary ligation-induced arrhythmia: After 1-2 days of coronary ligation, beagle dogs showed ventricular tachycardia; and as shown in Fig. 1, the values of the arrhythmic ratios were almost 1. 5 min before and just before injection ( 0 time). The preliminary experiments using $1-5 \mathrm{mg} / \mathrm{kg}$ of nicainoprol, i.v., showed that at doses of $1-3 \mathrm{mg} / \mathrm{kg}$, nicainoprol had almost no antiarrhythmic effect, and $5 \mathrm{mg} / \mathrm{kg}$ showed only a weak antiarrhythmic effect, but because of its central nervous system exciting effect, such as irritability and vomiting in 3 out of 6 dogs, higher doses could not be examined in $24 \mathrm{hr}$ after coronary ligation. As shown in Fig. 1, this dose decreased only the total heart rate. As shown in Fig. 2, arrhythmia was still present at $48 \mathrm{hr}$ after coronary ligation, and the plasma concentration of nicainoprol, just before the $48 \mathrm{hr}$ experiment, was zero, although $5 \mathrm{mg} / \mathrm{kg}$ had been administered $24 \mathrm{hr}$ before. The same 5 $\mathrm{mg} / \mathrm{kg}$ nicainoprol now showed antiarrhyth- 

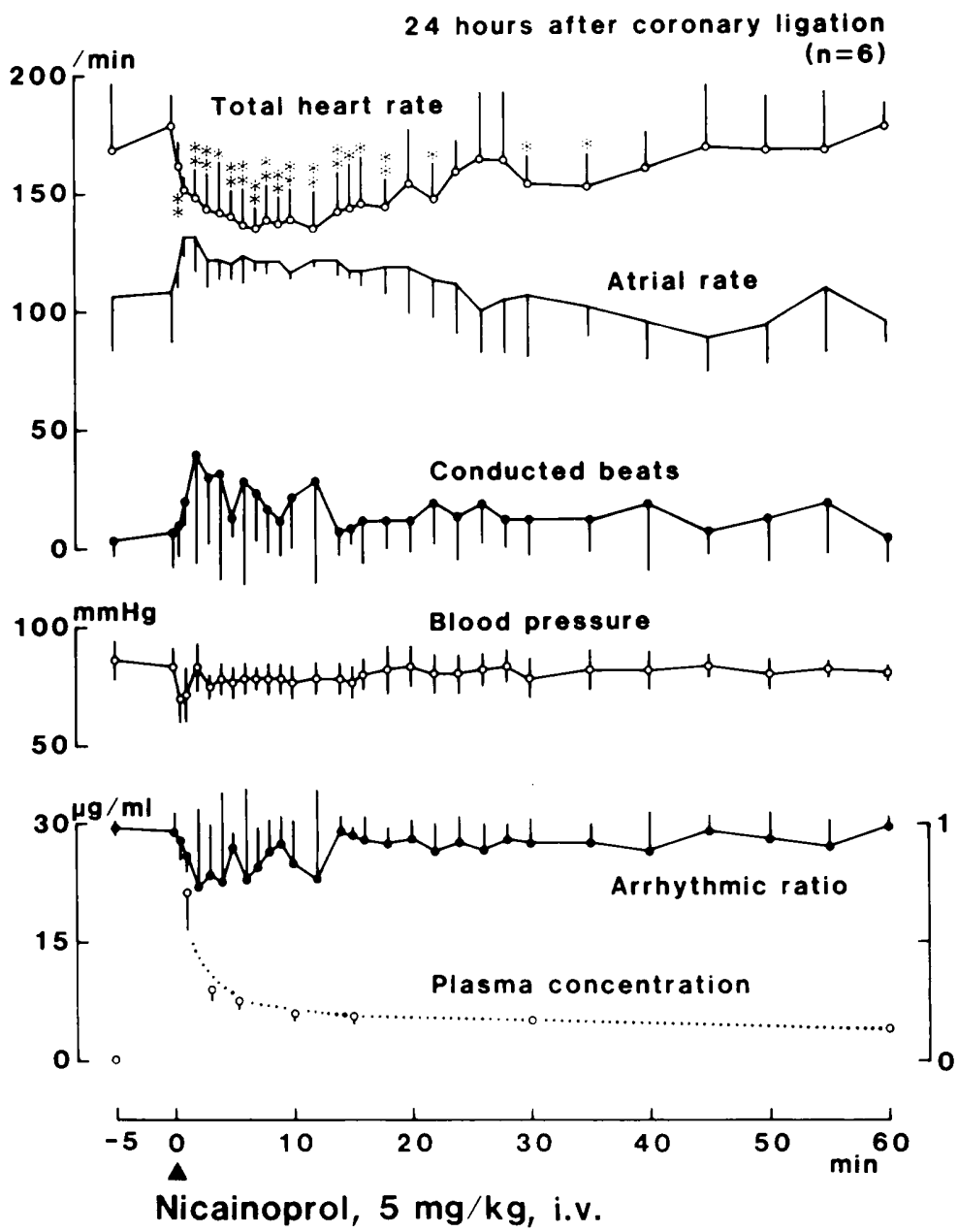

Fig. 1. Summary of the effect of nicainoprol on $24 \mathrm{hr}$ coronary ligation arrhythmia. Nicainoprol at $5 \mathrm{mg} / \mathrm{kg}$, i.v., decreased only the total heart rate. Vertica! bars represent standard deviation. ${ }^{*} P<0.05$. ${ }^{*} \mathrm{P}<0.01$.

mic effects lasting up to $24 \mathrm{~min}$, decreasing the arrhythmic ratio to almost 0 for nearly 10 min. Vomiting was observed again in 5 of the 7 dogs tested.

The plasma concentration-time curve fitted well with that predicted by the two-compartment open model. The parameters of the curve of the $24 \mathrm{hr}$ experiment were analyzed using the non-linear regression program "MULTI" (9) and an NEC PC-9801 Vm computer (Tokyo, Japan). The curve was expressed as concentration $\left(\mathrm{C}^{t}{ }_{p}\right)=\mathrm{Ae}^{-\alpha t}+\mathrm{Be}^{-\beta t}$, and the parameters were: $A=36.86 \pm 11.42$ $\mu \mathrm{g} / \mathrm{ml}$, alpha $=0.95 \pm 0.11 / \mathrm{min}, \mathrm{B}=7.07 \pm 1.22$ $\mu \mathrm{g} / \mathrm{ml}$, and beta $=0.012 \pm 0.003 / \mathrm{min} \quad(\mathrm{n}=6)$.
Those for the $48 \mathrm{hr}$ experiments were: $A=$ $38.98 \pm 27.14 \mu \mathrm{g} / \mathrm{ml}$, alpha $=0.74 \pm 0.18 / \mathrm{min}$, $\mathrm{B}=11.31 \pm 0.97 \mu \mathrm{g} / \mathrm{ml}$, and beta $=0.010 \pm$ $0.002 / \mathrm{min}(n=7)$. The minimum antiarrhythmic plasma concentration for the canine 48 hr coronary ligation-induced arrhythmia was calculated to be $8.9 \pm 0.8 \mu \mathrm{g} / \mathrm{ml}$ (at $24 \mathrm{~min}$ ).

The effect of oral administration of nicainoprol was examined in 7 other dogs after $24 \mathrm{hr}$ coronary ligation. We observed drug effects continuously up to $6 \mathrm{hr}$ after administration. After $30-40 \mathrm{mg} / \mathrm{kg}$ of nicainoprol, p.o., antiarrhythmic effects gradually appeared, as shown in the individual graphs of Fig. 3. The plasma concentration curves showed wide 

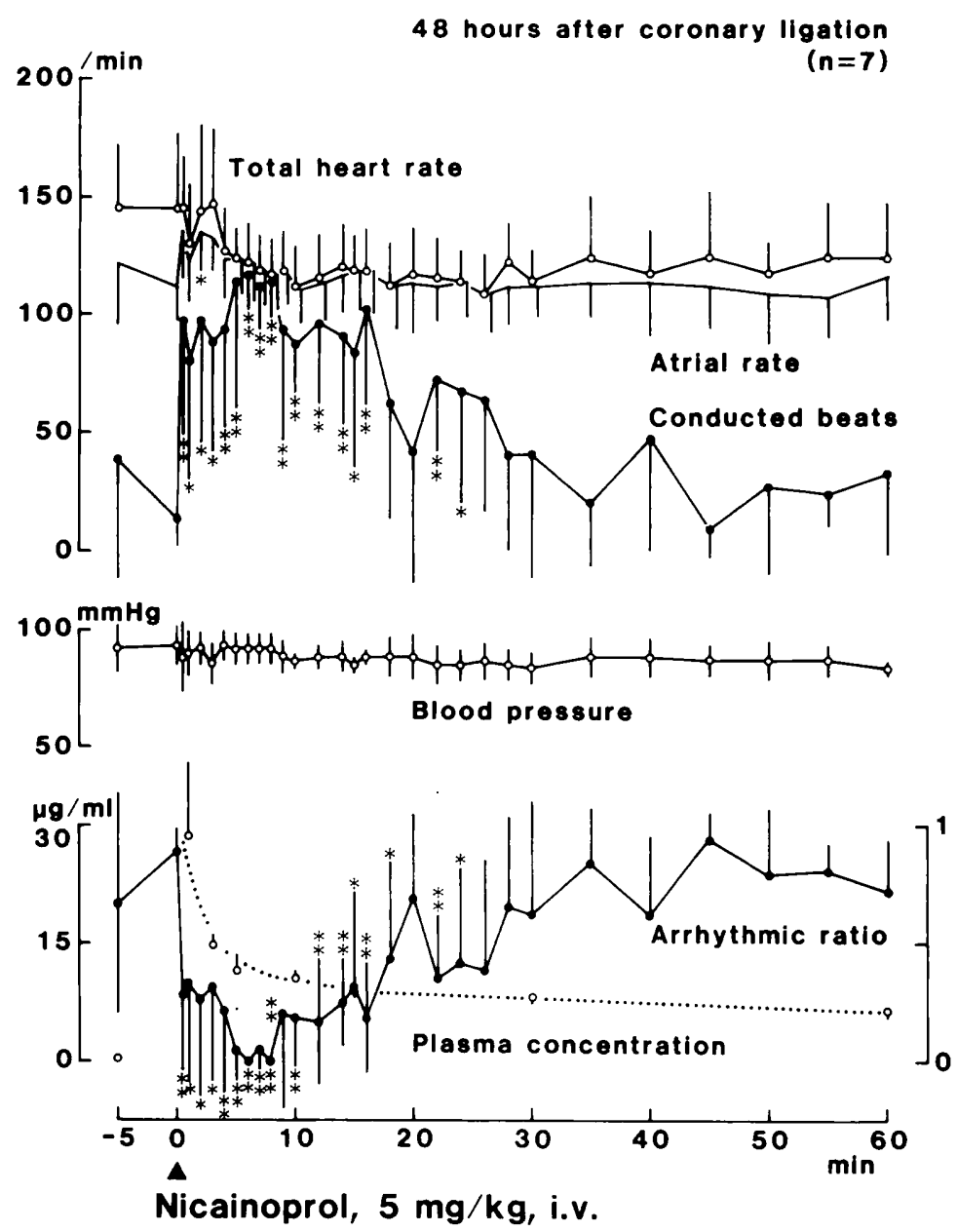

Fig. 2. Summary of effects of nicainoprol on $48 \mathrm{hr}$ coronary ligation arrhythmia. Five mg/kg, i.v., suppressed arrhythmia as shown by the increase in the number of conducted beats and the decrease of the arrhythmia ratio. ${ }^{*} \mathrm{P}<0.05,{ }^{*} \mathrm{P}<0.01$.

variety at the onset of the appearance of nicainoprol in the plasma and the time to peak concentration: thus, we could not draw figures of the summarized data. One dog that received $40 \mathrm{mg} / \mathrm{kg}$ died $100 \mathrm{~min}$ after administration due to gradual hypotension lasting for about $20 \mathrm{~min}$, without prominent antiarrhythmic response. The plasma concentrations at 30,60 and $90 \mathrm{~min}$ after administration were 1.17, 7.19 and $15.36 \mathrm{\mu g} / \mathrm{ml}$, respectively. The other 6 dogs also showed a tendency of low blood pressure at the time of peak plasma concentration, but the dogs did not show behavioral abnormalities, nor vomiting that was a common response after intravenous injection.

Effects of nicainoprol on digitalis-induced arrhythmia: After the intravenous injection of a total dose of $70-90 / \mathrm{gg} / \mathrm{kg}$ ouabain, almost all the beats were of ventricular origin, as shown in the -5 and 0 time values of arrhythmic ratio (Fig. 4). Nicainoprol at the doses of 1 to $3 \mathrm{mg} / \mathrm{kg}$ were examined in the preliminary experiments. Nicainoprol at a dose of $1 \mathrm{mg} / \mathrm{kg}$ showed only a weak antiarrhythmic effect; therefore, the dose of $3 \mathrm{mg} / \mathrm{kg}$ was chosen for this study. The arrhythmic ratio decreased from 3 to $40 \mathrm{~min}$ after injection. The plasma nicainoprol concentrationtime curves for each experiment fitted well 


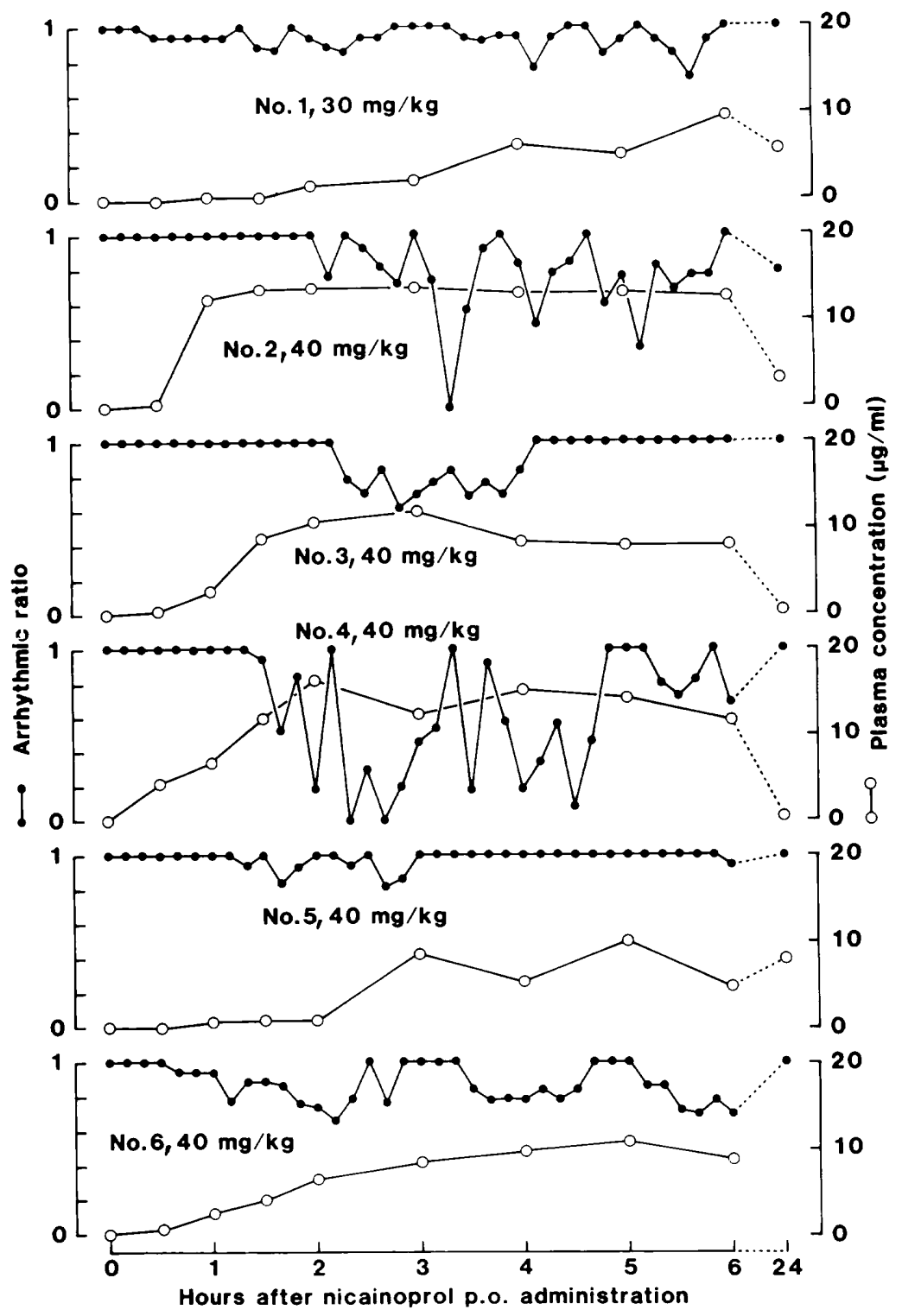

Fig. 3. Summary of effects of oral nicainoprol on $24 \mathrm{hr}$ coronary ligation arrhythmia. As the plasma concentration increases, decrease of arrhythmia ratio occurred.

with that predicted by the two-compartment open model. The parameters of the curves were: $A=29.36 \pm 6.17 \mu \mathrm{g} / \mathrm{ml}$, alpha $=0.636 \pm$ $0.205 / \mathrm{min}, B=4.52 \pm 2.09 / \mathrm{gg} / \mathrm{ml}$, and beta $=$ $0.012 \pm 0.002 / \mathrm{min} \quad(n=6)$. The calculated minimum antiarrhythmic plasma concentration of nicainoprol for canine digitalisinduced arrhythmia (at $40 \mathrm{~min}$ ) was $3.0 \pm 1.3$ $\mu \mathrm{g} / \mathrm{ml}$.
Effects of nicainoprol on adrenalineinduced arrhythmia: Adrenaline infusion at rates of $2.5-3.5 \mu \mathrm{g} / \mathrm{kg} / \mathrm{min}$ induced ventricular tachycardia of nearly 250 beats/min and consisted almost entirely of ventricular ectopic beats. Nicainoprol at the doses of 1-3 $\mathrm{mg} / \mathrm{kg}$ were examined in the preliminary study. Nicainoprol at the lowest dose of $1 \mathrm{mg} /$ $\mathrm{kg}$ had only a transient antiarrhythmic effect: 

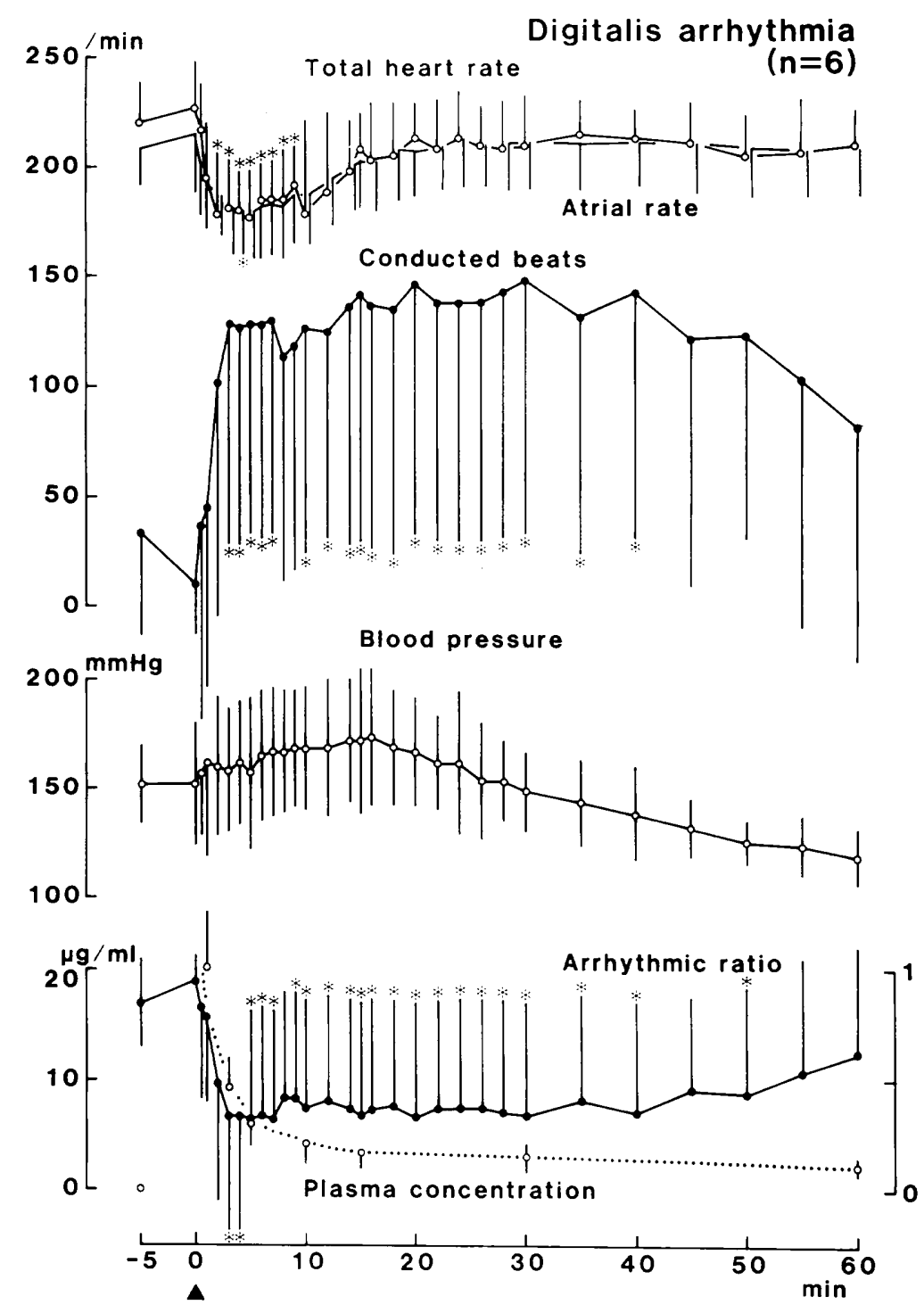

Nicainoprol, $3 \mathrm{mg} / \mathrm{kg}$, i.v.

Fig. 4. Summary of the effects of nicainoprol, $3 \mathrm{mg} / \mathrm{kg}$, i.v., on digitalis-induced arrhythmia. Nicainoprol decreased the total heart rate and arrhythmic ratio and increased the number of conducted beats. ${ }^{*} P<0.05$.

therefore, a dose of $3 \mathrm{mg} / \mathrm{kg}$ was used. As shown in Fig. 5, ventricular ectopic beats disappeared after injection of nicainoprol, and the arrhythmic ratio decreased to 0 and then gradually started to increase after $3 \mathrm{~min}$ after the injection. However, the statistically significant decrease lasted up to the last min of infusion of adrenaline, $15 \mathrm{~min}$. The plasma concentration-time curves of the short $15 \mathrm{~min}$ observation period fitted well that predicted by the one-compartment, open model theory. The parameters of the curves, which corresponded roughly to the distribution phase of the aforementioned two compartment model curves, were: $A=38.4 \pm 33.3 \mu \mathrm{g} / \mathrm{ml}$ and alpha $=0.381 \pm 0.243 / \mathrm{min} \quad(n=6)$. The antiarrhythmic nicainoprol plasma concentrations for canine adrenaline-induced arrhyth- 


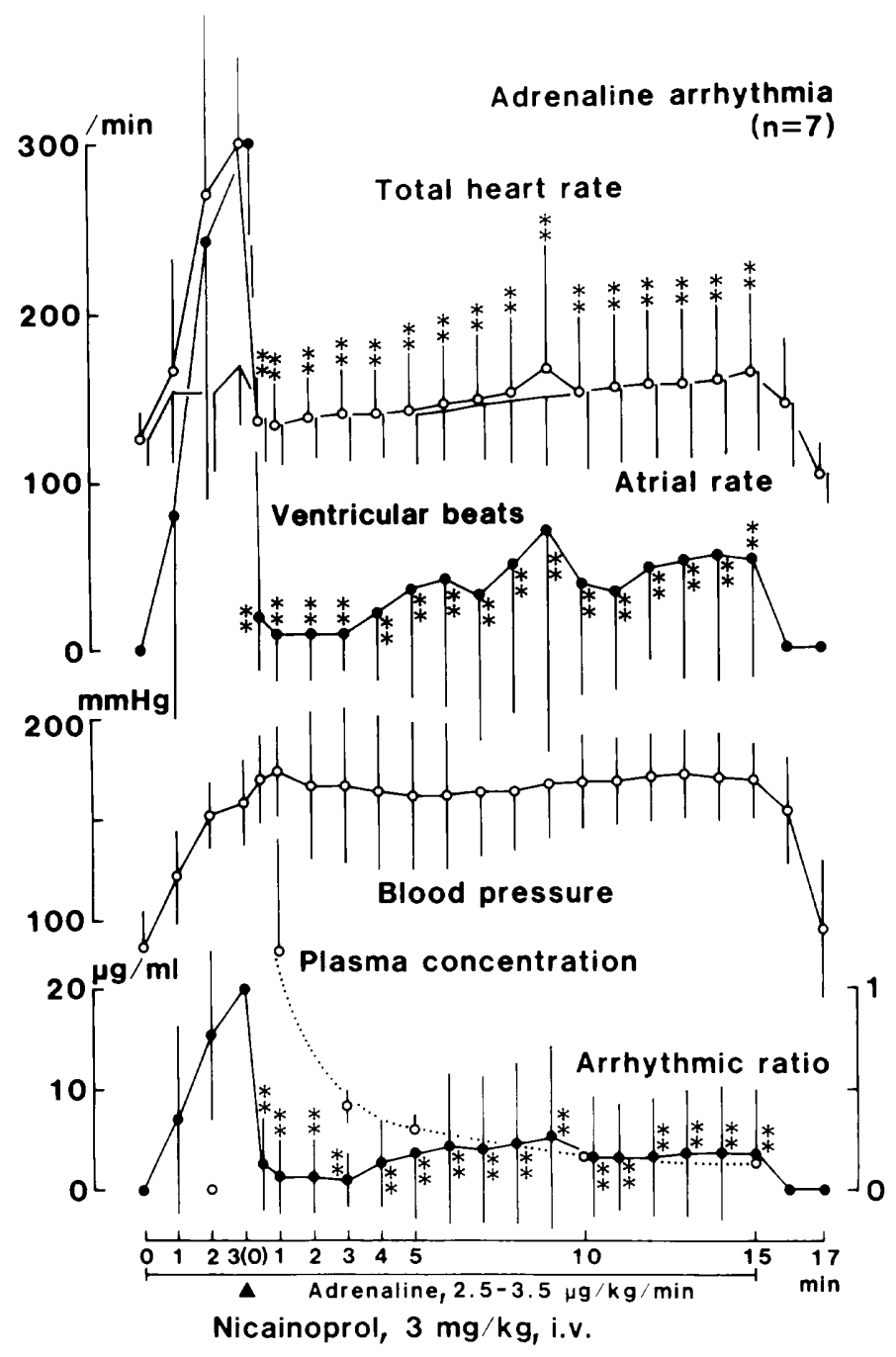

Fig. 5. Summary of the effects of nicainoprol, $3 \mathrm{mg} / \mathrm{kg}$, i.v., on halothane-adrenaline arrhythmia. Nicainoprol showed a long lasting antiarrhythmic effect up to the end of adrenaline infusion. ${ }^{* *} P<0.01$.

mia at $15 \mathrm{~min}$ was $2.7 \pm 0.8 \mathrm{~kg} / \mathrm{ml}$.

Relationship between nicainoprol plasma concentration and its antiarrhythmic effect: All the plasma concentration data and the corresponding values of the arrhythmic ratio obtained were plotted as in Fig. 6. Among the 5 straight lines, those of the coronary ligation arrhythmia experiments showed statistically significant correlations $(P<0.01)$, but the negative correlation coefficients ( $r$ ) were not as high (0.43-0.50). The two straight line relationships obtained from intravenous and oral administration experiments of $24 \mathrm{hr}$ coronary ligation arrhythmia were almost identical.

\section{Discussion}

The present experiment using three canine ventricular arrhythmia models confirmed previous reports (2) that nicainoprol is effective in animal experimental arrhythmias. Our experiment using $5 \mathrm{mg} / \mathrm{kg}$, i.v. and $30-40 \mathrm{mg} /$ $\mathrm{kg}$, p.o. of nicainoprol showed that it had antiarrhythmic effect on the coronary ligation arrhythmias, but simultaneously had central nervous excitatory effects including vomiting. 


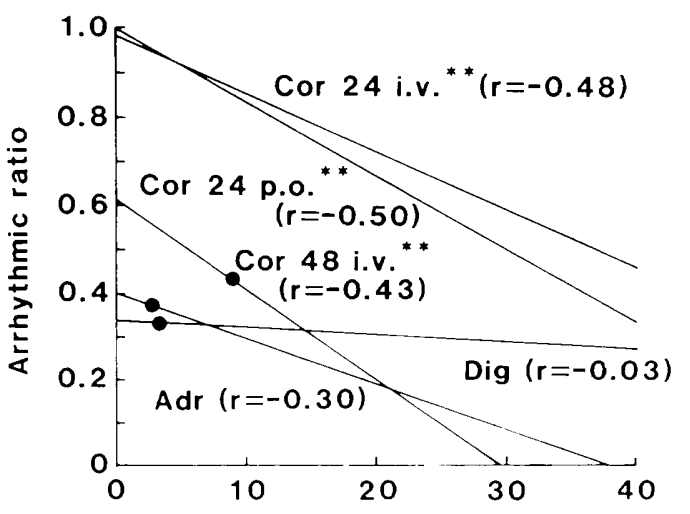

Nicainoprol plasma concentration $(\mu \mathrm{g} / \mathrm{ml})$

Fig. 6. Corlelation between plasma nicainoprol concentrations and its antiarrhythmic effects in 5 different experiments. Only the regression lines and the calculated minimum effective concentration on the line (filled circles) are shown. Cor 24 and Cor $48=24 \mathrm{hr}$ and 48 coronary ligation arrhythmia, Dig= digitalis arrhythmia, Adr=adrenaline arrhythmia. ${ }^{* *} \mathrm{P}<0.01$.

The minimum effective concentrations could only be determined for $48 \mathrm{hr}$ coronary ligation arrhythmia and was $8.9 \mathrm{~kg} / \mathrm{ml}$. However, as shown in the concentration-effect relationships of Fig. 6, nicainoprol had a concentration-dependent antiarrhythmic effect on $24 \mathrm{hr}$ coronary ligation arrhythmia (Fig. 6), but much higher concentrations must be required to decrease the arrhythmic ratio than that of the $48 \mathrm{hr}$ coronary ligation experiments. This may indicate that $24 \mathrm{hr}$ coronary ligation arrhythmia is more severe as compared to $48 \mathrm{hr}$ arrhythmia.

The antiarrhythmic plasma concentration for digitalis arrhythmia was $3.0 \mu \mathrm{g} / \mathrm{ml}$, significantly lower than those obtained in the coronary ligation arrhythmias. The in vivo threshold concentration of nicainoprol to induce $\mathrm{Na}$ channel depression was reported to be about $10^{-5} \mathrm{M}(1)$, i.e., $3.7 \mu \mathrm{g} / \mathrm{ml}$, so as we have already hypothesized (4), the antiarrhythmic mechanism of nicainoprol for digitalis and coronary ligation arrhythmias must be due to $\mathrm{Na}$ channel depression.

Our minimum effective plasma concentration data of nicainoprol shows that nicainoprol suppressed adrenaline induced arrhythmia also at a concentration less than $2.7 \mathrm{~kg} /$ $\mathrm{ml}$. Since nicainoprol has been shown to have weak beta blocking action, it is reasonable that this antiarrhythmic effect might be due to indirect $\mathrm{Ca}$ channel inhibition, through suppression of beta receptors, which is an important mechanism for suppression of the adrenaline arrhythmia (6)

Comparing the present results with our previous data on various antiarrhythmic drugs using the three ventricular arrhythmia models (Table 1), the pattern of effectiveness of nicainoprol is comparable to that of aprindine in that they have equipotent effects on digitalis and adrenaline arrhythmias, while they have a weaker effect on coronary ligation arrhythmia. As for the relatively weak antiarrhythmic activity on coronary ligation arrhythmia, propafenone is also similar to nicainoprol. Propafenone is a class $1 \mathrm{Na}$ channel blocking antiarrhythmic drug with beta blocking activity (5). Though the results of animal experiments do not necessarily mean effectiveness in patients, the results of the present experiments showing a wide range of effectiveness in dogs make us expect that nicainoprol may become a therapeutically effective drug.

The correlation of the plasma concentration of nicainoprol and its antiarrhythmic effect was examined as in our previous papers $(10-13)$. and it was again shown that there is a statistically significant correlation, but the negative correlation coefficients are not high. Thus the present study suggests again that the absolute values of the plasma concentration of an antiarrhythmic drug are less helpful in predicting the antiarrhythmic effects, while sequential determination of drug plasma concentration is useful in predicting changes in the antiarrhythmic effect and detecting the toxicity of drugs (13).

Since antiarrhythmic effects of nicainoprol were shown in animal models, and this drug has no serious cardiovascular and central nervous system side effects, if orally administered at proper dosage, it may be worth determining clinically whether nicainoprol can become a useful drug for ventricular arrhythmias.

Acknowledgments: The authors thank Nippon Roussel K.K., Tokyo for the gift of nicainoprol and for performing plasma concentration assays. We also 


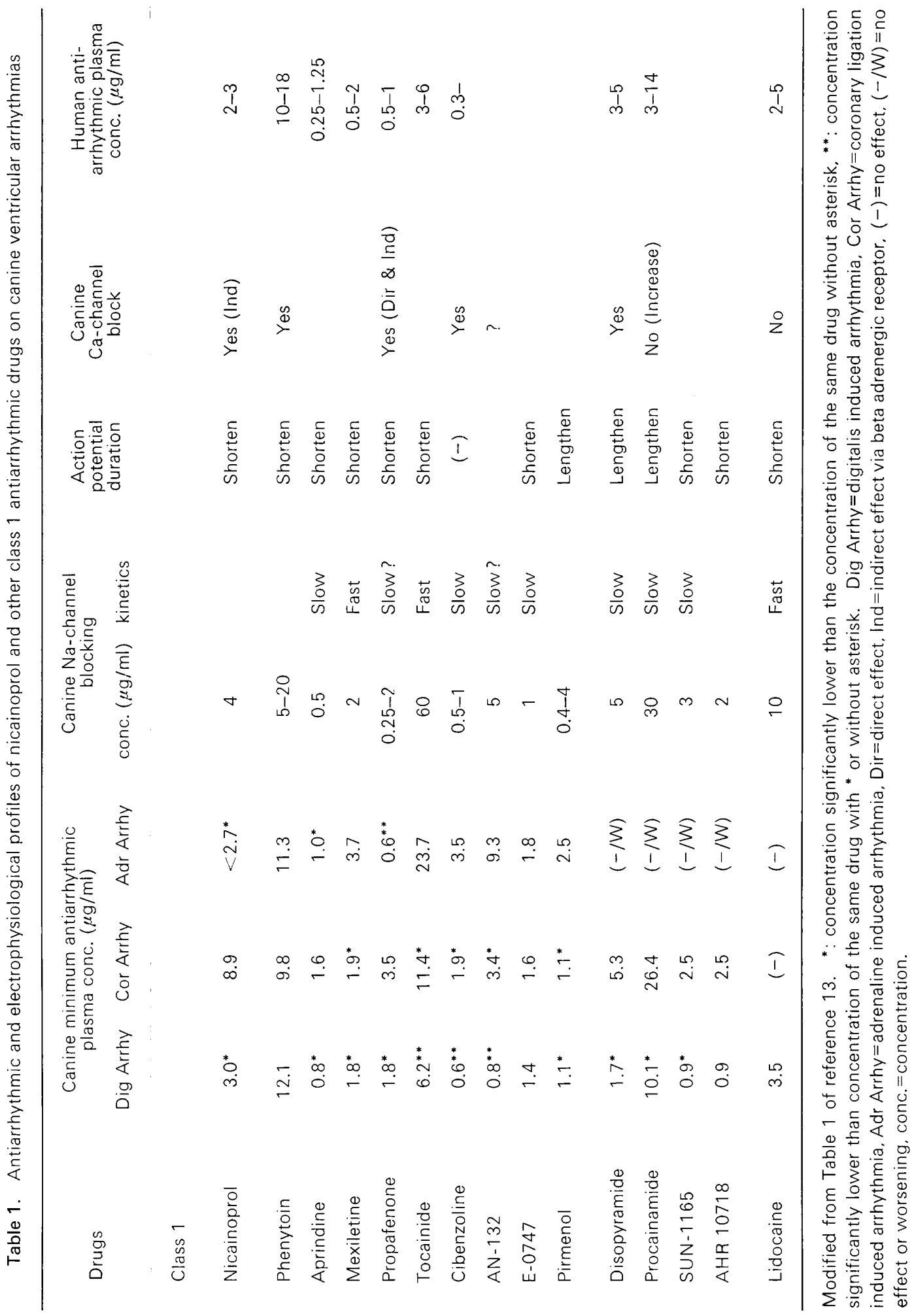


thank Miss M. Yamada and Miss M. Maruyama for their technical assistance.

\section{References}

1 Sawanobori, T., Hirano, Y., Adaniya, H., Yamashita, K., Hayami, H. and Hiraoka, M.: Electrophysiological effect of new antiarrhythmic drug -nicainoprol- on the various cardiac tissues. Shinzoh 19, 937-943 (1987) (in Japanese)

2 Hamon, G., Fortin, $M$. and Worcel, M.: $\beta$ Blocking properties of nicainoprol and propafenone [Abstract]. Eur. Heart J. 5, Supp. 1, 131 (1984)

3 Sen, S., Retting, G., Ozbek, C., Frohlig, G., Schieffer, $H$. and Bette, L.: Electrophysiological effects of a new antiarrhythmic agent, nicainoprol, in humans. J. Cardiovasc. Pharmacol. 8, 144-150 (1986)

4 Hashimoto, K., Satoh, H., Shibuya, T. and Imai, S.: Canine-effective plasma concentrations of antiarrhythmic drugs on the two-stage coronary ligation arrhythmia. J. Pharmacol. Exp. Ther. 223, 801-810 (1982)

5 Hashimoto, K., Ishii, M., Komori, S. and Mitsuhashi, $\mathrm{H}$.: Canine digitalis arrhytrmia as a model for detecting $\mathrm{Na}$-channel blocking antiarrhythmic drugs: A comparative study using other canine arrhythmia models and the new antiarrhythmic drugs, propafenone, tocainide, and SUN 1165. Heart Vessels 1, 29-35 (1985)

6 Shibuya, T., Hashimoto, K. and Imai, S.: Effective plasma concentrations of antiarrhythmic drugs against sustained halothane-adrenaline arrhythmia in dogs. J. Cardiovasc. Pharmacol. 5, 538-545 (1983)
7 Hashimoto, K.: Correlation between the antiarrhythmic effects of drugs on experimental ventricular arrhythmias and their cellular electrophysiological effects. In Pharmacology. Edited by Rand, M.J. and Raper, C., p. 497-500, Elsevier Science Publishers B.V., Amsterdam (1987)

8 Horai, Y. and Ishizaki, T.: Determination of nicainoprol, a new antiarrhythmic agent, in human plasma and urine by high-performance !iquid chromatography. J. Chromatogr. 383, 103-110 (1986)

9 Yamaoka, K., Tanigawa, Y., Nakagawa, T. and Ueno, T.: A pharmacokinetic analysis program (MULTI) for microcomputer. J. Pharmacobiodyn. 4, 879-885 (1981)

10 Hashimoto, K., Watanabe, K. and Sugiyama, A.: Antiarrhythmic plasma concentrations of pirmenol on canine ventricular arrhythmias. Japan. J. Pharmacol. 48, 273-282 (1988)

11 Hashimoto, K., Ishii, M. and Komori, S.: Antiarrhythmic plasma concentrations of mexiletine on canine ventricular arrhythmias. J. Cardiovasc. Pharmacol. 6, 213-219 (1984)

12 Hashimoto, K., Akiyama, K. and Mitsuhashi, H.: Antiarrhythmic plasma concentrations of cibenzoline on canine ventricular arrhythmias. J. Cardiovasc. Pharmacol. 9, 148-153 (1987)

13 Hashimoto, K.: Electrophysiological correlates of antiarrhythmic effects of drugs and phaimacokinetic principles examined using canine ventricular arrhythmias. In Cardiovascular Pharmacology '87, Results, Concepts and Perspectives. Fdited by Papp. J. Gy.. p. 79-93. Akademiai Kiads, Budapest (1987) 